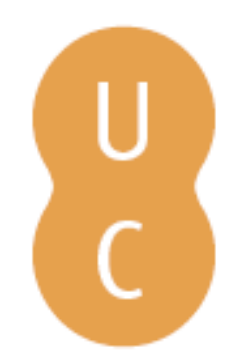

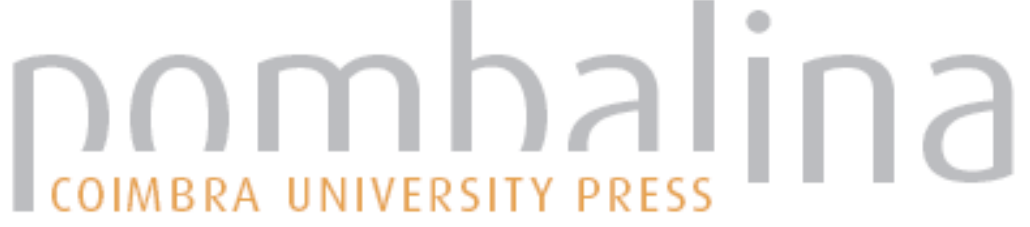

Como compreender e o que fazer com as críticas de Goethe à ciência newtoniana: os exemplos de Helmholtz e Heisenberg
Autor(es):
Videira, Antonio Augusto Passos
Publicado por: Imprensa da Universidade de Coimbra
URL
persistente:
URI:http://hdl.handle.net/10316.2/38448
DOI:
DOI:http://dx.doi.org/10.14195/978-989-26-0764-1_12
Accessed : $\quad$ 26-Apr-2023 11:05:47

A navegação consulta e descarregamento dos títulos inseridos nas Bibliotecas Digitais UC Digitalis, UC Pombalina e UC Impactum, pressupõem a aceitação plena e sem reservas dos Termos e Condições de Uso destas Bibliotecas Digitais, disponíveis em https://digitalis.uc.pt/pt-pt/termos.

Conforme exposto nos referidos Termos e Condições de Uso, o descarregamento de títulos de acesso restrito requer uma licença válida de autorização devendo o utilizador aceder ao(s) documento(s) a partir de um endereço de IP da instituição detentora da supramencionada licença.

Ao utilizador é apenas permitido o descarregamento para uso pessoal, pelo que o emprego do(s) título(s) descarregado(s) para outro fim, designadamente comercial, carece de autorização do respetivo autor ou editor da obra.

Na medida em que todas as obras da UC Digitalis se encontram protegidas pelo Código do Direito de Autor e Direitos Conexos e demais legislação aplicável, toda a cópia, parcial ou total, deste documento, nos casos em que é legalmente admitida, deverá conter ou fazer-se acompanhar por este aviso.

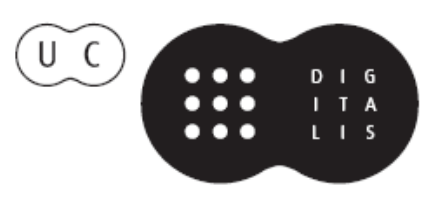


Universidade Estadual do Rio de Janeiro e Centro Nacional de Pesquisas guto@cbpf.br

\section{Como Compreender e o que Fazer com as Críticas de Goethe à Ciência Newtoniana: os Exemplos de Helmholtz e Heisenberg}

\section{Antonio Augusto Passos Videira}

Goethe é um caso curioso na história do pensamento europeu contemporâneo. Enquanto poeta e escritor, sua fama é universal, sendo ele aclamado, não apenas como um dos mais importantes literatos de língua alemã, mas também como um símbolo nacional na Alemanha, com repercussóes políticas importantes. Já a sua contribuição para as ciências naturais é, em geral, avaliada negativamente; o máximo que se lhe concede é uma certa relevância na constituição da morfologia como disciplina científica. As suas tentativas de formular uma teoria das cores para substituir aquela outra proposta por Newton um século antes teriam redundado em um fracasso retumbante, segundo os seus críticos. Esta tentativa serviu inclusive para empalidecer os feitos de Goethe no campo das ciências descritivas, como a botânica e a já mencionada morfologia. Em geral, as contribuições científicas nesses dois últimos domínios são encaradas, ainda hoje em dia, como relevantes e merecedoras de menção. No entanto, e desde que se tornaram conhecidas as suas críticas a Newton, a figura de Goethe sofre de uma duplicidade (ou ambivalência), responsável pela geração de uma série de efeitos negativos sobre a imagem que o ser humano faz de si próprio, destacando-se a divisão da sua personaldiade. De um lado, o homem de letras; do outro, e sem relação alguma com o primeiro, o homem de ciências. Justamente por ter cometido tais "erros", Goethe, nos domínios das histórias da ciência e das ideias, serviria principalmente como exemplo de uma má opção metodológica com graves consequências epistemológicas e metafísicas.

Com outro pensador, talvez fosse possível manter a imagem negativa acima esboçada. Em se tratando do autor de $A$ Doutrina das Cores, as coisas não são assim tão simples. Desconsiderando-se o tom antipático e virulento que usou para se referir a Newton, algumas críticas de Goethe às conceções de ciência e de natureza esposadas pela chamada ciência moderna são pertinentes, mesmo no domínio científico. Compreendê-las exige o entendimento da totalidade do seu projeto. Uma descrição desse projeto constituirá o primeiro objetivo deste artigo, o qual não pretende, em momento algum, ser considerado como uma análise completa ou rigorosa das ideias aqui apresentadas. Após a apresentação sumária de seu projeto, analisarse-ão declarações de Helmholtz e Heisenberg sobre as teses científicas de Goethe, observando-se à partida a necessidade de reconhecermos diferenças importantes entre aquele e outros 
membros da corrente da Naturphilosophie. A despeito das diferenças existentes nas críticas a Goethe, pode-se constatar uma perspetiva comum a praticamente todas elas: Goethe é acusado de tentar entender a natureza com o uso de princípios formulados a partir da sua visão de mundo, a qual teria sido construída sobre uma visão estetizante, não apenas da natureza, mas igualmente da vida. Em outras palavras, e incorrendo no mesmo tipo de erro cometido por seus oponentes, Goethe reduziria a dimensão intelectual humana a uma outra, a saber: aquela outra determinada pela sua própria sensibilidade.

O meu segundo objetivo será descrever as explicaçôes que eles elaboraram sobre os "erros" cometidos por Goethe. Finalmente, e à guisa de conclusão, me permitirei propor argumentos em favor da seguinte tese: o problema, formulado por Goethe em suas críticas à ótica newtoniana, teima em permanecer, ainda hoje, aberto e sem solução. Uma última palavra de advertência: ao afirmar que as críticas de Goethe permanecem continuar aguardando respostas convincentes, não quero concluir que elas são corretas sob o ponto de vista da ciência. Adotada a perspetiva científica, metodológica, e filosófica da ciência moderna, parece-me incontestável que elas não procedem. No entanto, se a perspetiva for outra, não acho que seja exagerado afirmar que Goethe conseguiu mostrar algumas das fragilidades dessa mesma perspetiva. Tais fragilidades - o uso irrestrito de hipóteses, por exemplo - constituíram tópicos das agendas de discussão filosóficas desde então.

O núcleo da estrutura deste texto encontra-se condensado nos seguintes temas: 1) O projeto científico de Goethe; 2) As críticas de Helmholtz e Heisenberg; e 3) Avaliação: é correto afirmar que o projeto de Goethe também seria reducionista ainda que de um tipo diferente daquele defendido pela ciência moderna, levando-o a ser incoerente? Estaríamos nós diante de uma escolha de Sofia: reducionismo estético versus reducionismo cientificista?

\section{Algumas datas da trajetória Científica de Goethe}

Nascido em 1749 e morto 82 anos depois, Goethe levou uma vida agitada e cheia de eventos admiráveis. Não constitui erro afirmar que a plenitude não era para ela uma meta válida apenas no plano das ideias (i.e., intelectual), mas ela deveria ser perseguida também na vida. De certo modo, tomar a plenitude como meta significava exibir uma preocupação com a diminuição da distância entre as ideias e as ações humanas. Somente a tentativa de negar essa distância não seria suficiente para realizar o projeto que Goethe defendia. Era necessário que, durante todo o processo de diminuição, reinasse um certo equilíbrio, o qual tinha lugar devido ao fato de que a ideia não era mais importante do que a ação, sendo o inverso igualmente verdadeiro.

Numa atitude ainda comum para o século XVIII, mas ortogonal àquela que vai se consolidar já na primeira metade do século seguinte, o poeta alemão dedicou-se a muitos e diferentes campos de estudo e investigação. Ao longo de sua vida, Goethe testemunhou o surgimento e o início de processo de consolidação da figura do especialista. São muitas as razões responsáveis pela presença - ainda que subjacente - do especialista nas críticas de Goethe à ciência. A meta de compreender a natureza deveria, para ele, ser possível a todo e qualquer ser humano. Em se tratando do autor 
de Fausto, merece destaque a sua suspeita de que a natureza somente poderia ser compreendida através do recurso da matemática.

Numa atitude contrária a alguns dos maiores expoentes científicos e intelectuais da segunda metade do Século das Luzes, como d'Alembert, Euler e Lagrange, Goethe via com muitas suspeitas as tentativas feitas em favor de conceder mais autonomia às ciências, como a mecânica, que usavam intensivamente a matemática. Esta última, mesmo após transcorridos cem anos da morte de Galileu, ainda almejava ser reconhecida como um conhecimento epistêmico válido. De forma sucinta, Goethe reconhecia validade epistêmica à matemática, mas desconfiava que tal validade fosse suficiente para garantir essa autonomia.

Apesar de não recusar completamente o uso da matemática, Goethe sempre preferiu os estudos empíricos, que lhe proporcionavam um tipo de experiência viva e plena com a natureza, aquela que se fazia presente através dos fenômenos da vida. Por isso, Goethe sempre privilegiou o estudo das plantas, animais e processos atmosféricos, na medida em que eles tornam possível ver a natureza como algo dinâmico.

Num período em que a especialização começava a ser predominante, a curiosidade intelectual imensa do autor de $A$ Natureza, abrangendo uma gama de assuntos muito variados, já o diferenciava - e muito - da maioria dos seus colegas investigadores. Segundo Goethe, a natureza deveria ser compreendida na sua totalidade. Investigá-la sob um aspeto específico, mesmo que importante e capaz de fornecer informações verdadeiras sobre o comportamento e a constituição da natureza, não seria suficiente para que se pudesse afirmar que esta útima teria sido compreendida. Abaixo algumas datas relevantes para que se possa perceber que Goethe dificilmente pode ser tomado como um especialista (ao contrário, ele deve ser visto como o oposto deste último):

1770/71 - Estudos em Estrasburgo

1775 - Primeiras investigações sobre ossos

1776 - Dedica-se à botânica

1777 - Observação de fenômenos cromáticos

1780 - Estudos de Mineralogia

1786 - Dedica-se também à álgebra

1790/1810 - Observação do comportamento espectral da luz leva-o a discordar das ideias de Newton. Até 1810, ano em que publica A Doutrina das Cores, Goethe dedica-se, ano após ano, a desenvolver uma conceção própria sobre a luz. Nestes anos, toma conhecimento através de comunicação enviada por Wilhelm von Humboldt dos escritos do português Diogo Carvalho e Sampayo 1808/12 - Realiza experiências químicas e sobre eletricidade (galvanismo)

1823 - Estudos de meteorologia

1830/31 - Dedica-se ao estudo da polêmica entre Saint-Hilaire e Cuvier.

\section{O PROJETO CIENTÍFICO DE GOETHE E A NATURPHILOSOPHIE}

Um dos mais importantes movimentos intelectuais - aqui compreendendo as dimensōes científica e filosófica - do final do século das Luzes e do início do século XIX, a Naturphilosophie pode ser considerado como uma reação consciente e radical 
contra as conceções de razão, natureza e conhecimento defendidas pelo Iluminismo. Como se sabe, este movimento tomou uma decisão de privilegiar objetivos epistêmicos como, por exemplo a comprovação, quantitativa e baseada na experiência, das descriçóes matemáticas (i.e. as leis naturais) propostas para os fenômenos. Já na época em que ocorreu, esta decisão foi compreendida como constituindo uma aposta no reducionismo, o qual, apesar de ser encarado como um compromisso com a ideia de que a natureza seria unificada, acabou por conduzir à direção contrária. A unidade da natureza, para Goethe e aliados, somente seria alcançada através do estudo da natureza enquanto totalidade e não como uma estrutura com níveis diferentes ente si, reunidos a partir da afirmação de que o nível mais fundamental seria o material. Assim, uma unidade que não conduzisse à totalidade seria de pouco interesse e mesmo de pouca valia.

Parafraseando um dos maiores conhecedores deste período, o historiador da filosofia Georges Gusdorf, devido à sua complexidade inerente, o universo enquanto totalidade torna-se passível de aproximação através das ciências, da razão, da poesia, da religião, das artes, bem como por via dos órgãos sensoriais. Organizando-se e movimentando-se por meio de dicotomias como visível e invisível, evidente e escondido, dentro e fora para superá-las, a investigação desse conhecimento global é a razão de ser da Naturphilosophie. A unificação ambicionada concretiza-ne no uso simultâneo de tais dicotomias, que conferem uma estrutura dinâmica ao processo de investigação.

Para se compreender o projeto científico de Goethe - a rigor, este projeto sempre foi pensando também a partir da filosofia e da poesia -, é necessário levar em consideração que ele se considerava o iniciador da Naturphilosophie e, por isso, responsável pelos seus desdobramentos. Em outras palavras, o poeta alemão defendia a necessidade de que a pesquisa sobre a natureza procurasse explicitamente respeitar a necessidade de se alcançar um equilíbrio entre os seus diferentes eixos estruturantes: razão, experimentação, conceitualização, quantificação, uso de imagens e hipóteses, entre outros.

A pesquisa acerca da natureza deveria respeitar obrigatoriamente o princípio de que o homem integra a natureza. Sem o respeito à essa presença, tornar-se-ia impossível a obtenção de uma compreensão total; esta última é possível graças à recusa consciente da tese de que o conhecimento funda-se - tem como seu ponto de partida - no isolamento do homem do cosmos que habita. Almejando a busca de uma coerência máxima, Goethe sempre procurou aproximar e fundir as diferentes dimensões da sua própria existência. Desse modo, seria um absurdo separar o Goethe-poeta do Goethe-cientista, aceitando que o autor do Fausto e da Doutrina das Cores levava uma existência dupla.

O sentimento de natureza, a relação espontânea com a natureza viva são anteriores em Goethe ao estudo refletido - ou conceitual ou ainda puramente intelectual - daquela; a reflexão sobre esta última não se reduz a uma compreensão conceitual, ela a ultrapassa. O objetivo para Goethe era, no caso da sua teoria das cores e mesmo para outros fenômenos naturais, formular uma descrição que fizesse uso de causas externas. Causa e efeito deveriam possuir um mesmo tipo, serem qualitativamente idênticas.

Goethe interessava-se em compreender a cor e não a natureza da luz: "As cores são ações e paixões da luz. (...) luz e cores se relacionam perfeitamente, embora devamos pensá-las como pertencentes à natureza como um todo: é ela inteira que assim quer se revelar ao sentido da visão." Uma segunda passagem sua que nos apresenta a mesma tese é uma outra datada de 1793, ano em que ele escreveu o seguinte a Jacobi: 
"A luz é o ser mais simples, indivisível e homogêneo que conhecemos. Ela não pode ser composta, muito menos de luzes coloridas".

Mesmo que de forma breve e superficial, não é fácil descrever a conceção sobre a natureza desenvolvida por Goethe. Além das muitas áreas que estudou, suas análises estão espalhadas por inúmeros e diferentes textos. A formulação de uma conceção unificada e inteligível da conceção de natureza de Goethe tomaria muito tempo. No entanto, dentre as muitas produções literárias e científicas de Goethe sobre a natureza, há uma que pode ser tomada como constituindo uma síntese de algumas de suas ideias; para nós, as mais importantes. Trata-se do poema A Natureza. Um trecho deste poema, que serve muito bem para ilustrar as ideias e os princípios basilares daquilo que ele pensava ser a natureza, é o seguinte ${ }^{1}$ :

"Natureza! Por ela rodeado e a ela ligados, não nos é permitido sair do seu amplexo, nem penetrar nela mais profundamente. Sem lho pedirmos e sem nos avisar, ela acolhe-nos no vórtice da sua dança, e lança-se conosco, até que, cansados, caíamos nos seus braços.

Eternamente ela cria novas formas: aquilo que agora existe não existiu nunca, aquilo que existiu não volta: tudo é novo, embora sempre velho.

Vivemos nela e somos-lhe estranhos. Incessantemente fala conosco, mas não nos revela os seus mistérios. Continuamente atuamos sobre ela, embora sobre ela não tenhamos qualquer poder. O seu objetivo parece ser o indivíduo, embora não saiba que fazer do indivíduo. Sempre ela cria e sempre ela destrói, mas a sua oficina é inacessível.

Ela vive plenamente nas suas criaturas, mas a mãe onde está? Ela é a única artífice: das criações mais simples passa às mais complexas, às mais perfeitas sem qualquer aparência de esforço, com a máxima precisão e sempre com delicadeza. Cada uma das suas obras tem a sua fisionomia própria, cada uma das suas manifestaçôes tem o seu sgnificado próprio, embora seja parte de um só todo. [...]

Nela há um eterno viver, um eterno devir, um eterno movimento, embora não avance um passo. Transforma-se eternamente, e não tem um momento de pausa. Não sabe deter-se, e cobre de maldições a pausa. No entanto, está parada, e o seu passo é comedido, as suas exceções raras, as suas leis imutáveis [...].

A cada um aparece sob uma forma própria: sob mil nomes e formas se oculta, e é sempre a mesma. Ela trouxe-me a este mundo, e deste mundo me fará sair. Confio-me a ela. Ela pode contar comigo. Não odiará a sua obra. Mas não falei dela. Não: quanto é verdadeiro e quanto é falso, tudo foi dito por ela. Tudo é minha culpa, tudo é seu mérito" ( $A$ Natureza, 1798).

\section{GoETHE, A ÓTICA NEWTONIANA E ALGUNS DE SEUS CRÍTICOS}

Goethe interpreta as cores a partir do órgão da visão, que não se confunde com prismas e lentes: o olho é um órgão vivo. Ele rejeita experimentos realizados em quartos escuros, como aqueles conduzidos por Newton. Para ele, a investigação ao ar livre, onde o olhar reencontra a natureza, é a única que o atrai. O uso de hipóteses - afirmações não comprovadas sobre a natureza dos corpos e fenômenos naturais - era

${ }^{1}$ Usamos aqui a tradução portuguesa que se encontra em Paolo CASINI, As filosofias da natureza,. Lisboa: Verbo, s.d. 
criticado por Goethe, uma vez que ele temia que a elaboração de teorias descritivas ficasse como que presa à tarefa de comprovar, ou refutar, tais hipóteses. Um tal comportamento metodológico seria completamente inadequado.

Como já afirmado anteriormente, o pensamento de Goethe, quando analisado pelos critérios de cientificidade usualmente empregados, recebe, em geral, uma avaliação claramente negativa. Isso é muito conhecido e não precisa ser repetido aqui, ao menos não neste momento - trataremos disso em outros momentos do presente texto. Para além da avaliação negativa, e o que me parece ser ainda mais relevante, as tentativas de Goethe são consideradas, por esses avaliadores, como se fossem um caso isolado, isto é, ninguém, além dele, teria tentado propor uma explicação para a natureza da cor diferente daquela avançada pelo filósofo natural inglês. No máximo, quando se tenta diminuir o impacto negativo dos comentários das ideias de Goethe sobre a ótica, concede-se a elas a possibilidade de serem inseridas numa perspectica filosófica, ou o que seria o mesmo, não científica. Nada, contudo, mais distante da verdade do que tomar as propostas de Goethe como isoladas e não científicas. Ainda que isso possa significar a revisão da tese, hoje amplamente aceita, de que a ciência moderna era, ao final do século XVIII e no início do seguinte, como a conhecemos hoje, creio ser imperioso defender o contrário. No momento em que Goethe propõe a sua teoria das cores, não nos esqueçamos que ele começou a desenvolvê-la ainda na década de 1790, a ótica newtoniana não era considerada como um paradigma, em que pese o reconhecimento público da sua capacidade descritiva e preditiva. Além disso, também no momento mesmo em que Goethe publica a sua versão definitiva sobre as cores no texto $A$ Doutrina das Cores, a ótica newtoniana começava a sofrer a concorrência da perspetiva ondulatória defendida por Young.

Para o objetivo maior deste texto, - a saber: exibir a coerência intrínseca das ideias do poeta alemão relativas à sua análise da conceção moderna de ciência, tomando como exemplo a sua própria conceção de cor-, vale a pena mencionar, ainda que muito brevemente, as ideias de um diletante, desta vez português, sobre o mesmo assunto. Trata-se de Diogo de Carvalho e Sampayo, nascido em 1750 e morto 56 anos depois, formado em Direito e que excerceu, entre outros cargos administrativos, o de embaixador da corte portuguesa em Madrid. A nossa apresentação das ideias de Carvalho e Sampayo segue de perto aquela outra formualda por Rui Graça Feijó, responsável pela reedição recente das obras de Carvalho e Sampayo, e que veio a luz no de $2008 .^{2}$ Não se pode aqui, infelizmente, esmiuçar as ideias de Carvalho e Sampayo. O meu objetivo resume-se a chamar a atenção para o fato de que ele, como Goethe, quem conhecia suas ideias e as comentou, parece ter acreditado que, para que se fosse possível propor o que quer que seja sobre a natureza das cores, era obrigatório que se fosse um diletante, ou um amador, como diríamos atualmente. $\mathrm{O}$ especialista manteria compromissos com as regras internas das sua especialidade, o que o impediria de vivenciar o fenômeno tal como este deveria: "Ela [a sua Dissertação sobre as cores primitivas] não se funda em arbitrárias suposições, mas sim nas mais decisivas experiências, e naturais analogias, que são as verdadeiras provas desta sorte de conhecimento" (CARVALHO E SAMPAYO 2008, p. 82).

${ }^{2}$ O Sistema das Cores (introdução e coordenação editorial Rui Graça Feijó). Porto: Porto Editora, 2008. 
Quando Carvalho e Sampayo afirma ter realiazado experiências, é bom se ter em mente aquilo que entende por este vocábulo. É justamente aqui - na sua conceção do que é uma experiência verdadeira e autêntica - que se pode verificar uma das mais relevantes semelhanças com Goethe, desfazendo a tese de que este seria um caso isolado e,portanto, uma aberração. De forma resumida, pode-se dizer que a noção de experiência de Carvalho e Sampayo não reduz as cores à luz branca; isto seria mesmo interditado e, mais importante, deveria permitir a geração das outras cores. Ou seja: o jurista, embaixador e amador das ciências naturais português não acreditava ser possível compreender o mundo a partir da negação daquilo que era entendido como sendo responsável pela sua constituição.

Carvalho e Sampayo defendia a tese de que o conhecimento da natureza era universal. Talvez fosse mais correto afirmar que a universalidade das cores permitia a pretenção de um conhecimento universal sobre a natureza. A universalidade do conhecimento deveria ser imanente, ou inerente, ao próprio mundo:

\begin{abstract}
"As cores são a mais universal e interessante parte de toda a Física: elas ornam todo o Universo, e a elas devemos todos os nossos naturais conhecimentos. Desde a mais remota estrela fixa até a mais profunda escavação feita no nosso globo, não se vê corpo algum, que não seja colorido. As ideias de todos esses corpos formam a universalidade dos nossos naturais conhecimentos, e estas ideias são o resultado de uma sucessiva pintura, que se renova a cada instante dentro de nossos olhos" (CARVALHO E SAMPAYO 2008, p. 82).
\end{abstract}

Desde o momento em que se tornaram públicas, as ideias de Goethe foram alvo de imensa e intensa atenção por parte de cientistas, sobressaindo-se naturalmente os físicos. Entre a primeira metade do século XIX e o final do século passado, muitos físicos se ocuparam com as críticas de Goethe à ótica/ciência newtoniana. A título de exemplo, os seguintes nomes podem ser citados: Brandeis, Posegeler, Born, Heitler, von Weizsäcker, Young, Brewster, Tyndall, Wien, entre outros. No restante deste texto, a nossa atenção estará ocupada por apenas dois deles: Helmholtz e Heisenberg. A razão para essa escolha é simples. Helmholtz e Heisenberg foram os físicos que mais vezes voltaram a Goethe, dedicando a eles ou bem trabalhos específicos ou bem mencionando o seu nome várias vezes. A importância concedida a Goethe era tamanha que, muitas das suas opiniōes sobre este, foram exprimidas em palestras dadas na Sociedade Goethe. A segunda razão, e mais importante, diz respeito à relevância que deram à crítica de seu compatriota. Helmholtz e Heisenberg compreenderam bem a motivação das críticas do autor de A Doutrina das Cores à ótica newtoniana. Assim, para eles, responder criticamente a Goethe significava dar conta dessa motivação. As suas respostas não poderiam se restringir apenas aos aspetos científicos da polêmica sob pena de não serem capazes de responder e suplantar os óbices de Goethe.

Para o caso específico de Heisenberg, uma terceira razão pode ser incluída. A despeito de não termos provas diretas, com a exceção do trecho que será citado abaixo, o formulador do princípio de incerteza percebia que as críticas de Goethe somente seriam plenamente respondidas caso fosse superada a cisão entre os diferentes domínios do conhecimento humano e que essa superação espelhasse a unidade profunda existente na natureza, reaproximando conhecimento científico e vida humana. 
Um outro fator que não deve ser esquecido, a despeito de nós aqui não o discutirmos, é que o nome de Goethe se faz acompanhar, com frequência considerável, de disputas políticas e ideológicas, como por exemplo aquelas que existiram após a ascenção do Nazismo. Para corroborar tal lembrança, basta mencionar as disputas que envolveram Heisenberg, de um lado, e Philipp Lenard e Johannes Stark de outro.

\section{As duas AVAliaçốes de Helmholtz: 1853 e 1892}

Hermann von Helmholtz dedicou duas longas palestras à análise das ideias de Goethe. Entre elas, temos um hiato de praticamente 40 anos. A segunda delas foi a última palestra que proferiu para o grande público.

Para melhor situar a relação entre os pensamentos destes dois ícones da cultura alemã, é preciso mencionar que até o início da década de 1840, a física, bem como outras ciências naturais, ainda não desfrutava de uma posição institucional sólida. Aliás, as próprias universidades ainda estavam se adaptando ao modelo humboldtiano - proposto na primeira década dos oitocentos, que vinculava estreitamente ensino e pesquisa. A fase inicial da carreria de Helmholtz foi testemunho da disputa por maior reconhecimento por parte dos cientistas. As ciências naturais ainda não gozavam do devido respeito e não despertavam o interesse das camadas cultas alemãs.

As duas palestras de Helmholtz foram dadas em um tom respeitoso, ainda que a segunda mostre mais proximidade, ou seja, maior concordância, com as ideias do poeta alemão. Na palestra de 1853, o codescobridor do princípio da conservação da energia mostra-se mais crítico e impaciente com as teses científicas do seu contemporâneo. Em questão, estariam o objetivo da ciência e o método adequado para atingi-lo. Para Helmholtz, Goethe possuía uma capacidade notável de descrição. No entanto, suas descrições eram artísticas e não científicas, uma vez que eram obrigadas a respeitar a intuição e não a razão. O fenômeno descrito seria a expressão direta da ideia. Em suma, Goethe erraria ao insistir numa aproximação entre ciência e arte. A natureza deveria revelar os seus segredos de livre e espontânea vontade. Isso não era suficiente, uma vez que em toda e qualquer explicação dos fenômenos naturais, deve-se abandonar a região dos sentidos e passar para coisas, que não são objetos, definidas por conceções abstratas. Contudo, sempre segundo Helmholtz, Goethe temia dar este passo em direção a conceções abstratas, mesmo tendo ele que ser necessariamente dado, caso se queira penetrar nas causas dos fenômenos.

Helmholtz nunca deixou de acreditar que as críticas de Goethe a Newton eram equivocadas, quando avaliadas a partir da perspetiva científica. A razão pela qual Goethe divergiu do físico inglês origina-se no divórcio instaurado na conceção filosófica da sensação, separada, a partir de agora, da sua apreensão fenomênica.

$\mathrm{Na}$ sua segunda palestra sobre Goethe, apesar da divergência com aquele, Helmholtz, preocupado em como manter vivo o espírito adequado à pesquisa - principalmente entre os jovens - defendia o trabalho árduo, somente possível graças ao método indutivo. Essa defesa do método indutivo, uma das marcas registradas do pensamento filosófico do poeta, fez com que o físico revisse suas posiçôes iniciais, amenizando-as. Assim, em 1892, ele afirmou o seguinte: 
"Como conclusão, podemos resumir as nossas consideraçōes do seguinte modo: onde se trata de problemas, que podem ser resolvidos pela poesia por meio de imagens intuitivas, o Poeta mostrou ser capaz de atingir os resultados os mais notáveis; onde apenas o método indutivo, conscientemente aplicado, pode ser de alguma valia, ele fracassou. Contudo, uma vez mais, onde se trata das questóes as mais elevadas a respeito da relação entre razão e realidade, sua adesão saudável à realidade o protegia das aberrações e o conduzia, de forma segura, a suposições [consideraçôes] que alcançavam os limites do entendimento humano."3

\section{Heisenberg e Goethe: Budapeste, 1941}

Tal como Helmholtz, que à época de sua morte - 1894, era o decano da física alemã, Werner Heisenberg, após o desaparecimento de Max Planck em 1947, passou a representar o papel de expoente maior dessa ciência em seu país. Assim, e seguindo uma tradição local, o cocriador da versão matricial da mecânica quântica, procurou formular uma conceção de natureza, bem como uma outra de ciência, capaz de determinar um lugar adequado para aquele que, desde o século XIX, era o símbolo maior da cultura alemã. Segundo Elisabeth, esposa de Heisenberg, Goethe foi uma companhia constante durante toda a sua vida.

Em 1941, Heisenberg deu várias palestras em diferentes cidades europeias ocupadas pelas forças militares nazistas. Foi nesse mesmo ano que aconteceu em Copenhague o célebre e até hoje mal compreendido encontro entre o físico alemão e Niels Bohr. Além da capital dinamarquesa, Heisenberg visitou Budapeste com o mesmo propósito: aproximar, através da cultura germânica, os alemães dos povos ocupados. Na capital húngara, ele proferiu uma palestra sobre as críticas de Goethe à ótica newtoniana, palestra posteriormente publicada em livro. Na versão húngara da palestra, há uma nota, cujo autor é ignorado e que foi inserida como um apêndice, que não se encontra no original alemão e em suas traduções. Esta nota é digna de interesse, uma vez que ela não somente reproduz aquele que parece ser o verdadeiro objetivo de Heisenberg naquela ocasião, mas o reforça de um modo muito pouco comum para um cientista natural. Ainda que ele provavelmente não seja o autor desse breve apêndice, a postura de Heisenberg naquele período era coerente com o que ali se lê. O conteúdo desse apêndice é o seguinte:

"Esta palestra origina-se de uma comparação dos fundamentos das teorias das cores de Goethe e de Newton com os fundamentos do domínio de realidade, para o qual ambas teorias das cores são válidas. Será enfatizado que a física atômica moderna ultrapassa o domínio de realidade da física newtoniana, bem como também que a perseguição consequente do caminho estabelecido por Galileu e Newton conduz a um domínio que se diferencia fundamentalmente daquele [presente] na física clássica. Desse estado de coisas, pode-se extrair a esperança de que num tempo não muito distante será possível abrir [uma vereda] para o entendimento da vinculação entre os domínios das [ciências] naturais e [as] do espírito.” (Heisenberg apud Loren Graham)4

${ }^{3}$ HELMHOLTZ 1995, On Goethe's Scientific Researches IN Helmholtz, Hermann von. Science and Culture: Popular and Philosophical Essays. Chicago/London: The University of Chicago Press. pp. 1-17.

${ }^{4}$ GRAHAM, Loren 1981. Between Science and Values, New York: Columbia University Press. No livro deste autor, a citação está em alemão. A tradução para o português é minha. 
Um segundo esforço de Heisenberg em direção à construção de uma tal vereda é o manuscrito $A$ Ordenação da Realidade, redigido durante a guerra e somente publicado alguns anos após a sua morte ocorrida em 1976. O reconhecimento da influência do pensamento de Goethe já se encontra no título, atribuído pelos organizadores das obras completas do físico alemão. Uma segunda característica nos permite igualmente ver o quanto Heisenberg tinha sido marcado por Goethe. Heisenberg recusou-se sempre a formular uma filosofia sistemática e geral, bem como não procurou - jamais - criar uma visão de mundo.

Entre os muitos intelectuais que dialogaram com as teses de Goethe, muitas vezes percebido como um personagem central para a construção de imagens de natureza, com as suas consequências positivas e negativas, o tema da técnica não poderia ser deixado de lado, uma vez que, a partir do início dos novecentos, a técnica era aquilo que mais preocupava os espíritos que se consideravam esclarecidos. Até então, a técnica era vista ou como existindo de forma independente da ciência ou, o que seria o melhor dos casos, dependia desta última. A partir do momento em que a indústria passou a ser mais importante força econômica das nações desenvolvidas, a técnica ganhou uma presença e uma relevância na sociedade, bem como nas esferas que a constituem como a cultura e que são vistas como as responsáveis pela elaboração de questionamentos acerca da sua posição frente à ciência. Entre outros, passou a ser tema de discussão se a ciência aplicada (i.e., a técnica) seria mais importante e, portanto, merecedora de receber mais apoios, do que a ciência.

A técnica, contudo, não era objeto de discussão apenas por conta da relevância econômica ou da sua relação com a ciência. Era necessário se perguntar de que modo ela poderia afetar a existência da humanidade. Será que o modo de existência dos seres humanos sofreria modificaçôes notáveis provocadas pela técnica? Sempre segundo Heisenberg, não havia como desconsiderar a técnica em qualquer reflexão sobre a ciência ou sobre a natureza. Também aqui, a influência de Goethe, que sempre temeu os efeitos nocivos da técnica, era evidente. Para o físico alemão, a situação era absolutamente radical e deveria ser encarada como tal, uma vez que, pela primeira vez na história humana, o homem se encontraria só consigo mesmo sobre a Terra, sem poder recorrer a ninguém, seja para apoiá-lo, seja atacá-lo.

O homem por toda a parte se depararia com suas criações espalhadas pela Terra, situação que acabaria por convertê-las em seu meio ambiente. Tal situação faz com que aparentemente não mais exista uma natureza que se contraponha ao homem, assim como nada que ultrapasse a instância das produçôes humanas. $\mathrm{O}$ verdadeiro objeto da investigação humana não seria mais a natureza em si, mas a natureza tal como esta pode ser interrogada pela razão humana.

\section{Conclusốes}

Uma das razões que explicam a presença de Goethe entre intelectuais e cientistas, e não apenas entre poetas, filósofos e artistas, foi que nas suas críticas à ciência newtoniana ele a acusou de não abrigar o homem. Em outras palavras, na natureza, tal como concebida (i.e. descrita e explicada) pela ciência moderna, o homem seria um estranho para aquela. Ou ainda: a conceção de natureza da ciência moderna seria fria e indiferente ao 
homem. As leis naturais somente poderiam ser formuladas caso o homem se ausentasse dos fenômenos descritos.

Ao preferir estudar a cor e não o fenômeno da luz, Goethe deixava claro com esta sua escolha que o homem não poderia ser posto de lado, uma vez que a cor só pode ser concebida a partir da sua presença. Ao rejeitar a conceção de natureza da ciência moderna, Goethe recusava também aquilo que esta defendia como sendo verdade e objetividade. Também a sua suspeita da importantância e utilidade da matemática para as ciências naturais explica-se por esse motivo, a saber: Goethe não aceitava que o conhecimento pudesse se tornar autônomo com relação aos fins e aos propósitos humanos. Caso isso acontecesse, o conhecimento voltar-se-ia contra a humanidade.

Em que pese o (grande) risco de um reducionismo de minha parte, creio não ser incorreto defender a tese de que uma das mais importantes preocupações de Goethe pode ser formulada sob forma de questão, a saber: como elaborar uma noção de ciência da natureza, que incorpore a criatividade humana em toda a sua complexidade multifacetária, e faça desta potência criativa humana uma de suas características constitutivas? De modo também esquemático, penso que para ele nenhuma esfera da vida humana, principalmente se tal esfera fosse intelectual ou espiritual, mereceria ser desconsiderada. A capacidade de inclusão daquele que para muitos é o mais importante poeta de todos os tempos é admirável e foi reconhecida, mesmo que a contragosto, por muitos dos seus mais brilhantes adversários: os cientistas naturais.

A necessidade autêntica sentida por muitos deles em tentar compreender e responder ao genial poeta exibe que este último, ao visar Newton, tinha deliberadamente tocado em pontos sensíveis do projeto científico da Modernidade. Quando bem compreendidas, as suas críticas mostram que a defesa desse mesmo projeto não pode ser feita apenas com a repetição do sucesso empírico-preditivo da ciência. A despeito da sua importância cognitiva, os resultados científicos não são suficientes para responder às provocações e críticas epistemológicas, metodológicas e metafísicas de Goethe.

Dentre os defensores conscientes do projeto da ciência moderna, aqueles que mais aceitaram essas provocações e críticas foram Helmholtz e Heisenberg. O primeiro considerava que a ênfase do poeta, como ele gostava de se referir a Goethe, na descrição era excessiva, pois impedia o uso de abstrações. O mesmo se passava com a condenação da matemática; esta última possuía força heurística considerável e de muita utilidade para os cientistas na busca por explicaçôes bem sucedidas empiricamente dos fenômenos naturais. Apesar de tais divergências, Helmholtz reconhecia e apreciava a independência do espírito do poeta.

Quando comparado a Helmholtz, Heisenberg posicionou-se mais favoravelmente do autor de Fausto. Não é improvável que sua proximidade com ele explique-se pelo tempo em que viveu. Tal como fica claro na sua análise da natureza da técnica, Heisenberg sabia muito bem as consequências negativas que a ciência e suas aplicaçôes geravam. Somando-se a tal conhecimento, e mais uma vez se diferenciando de Helmholtz, Heisenberg tentou encontrar vínculos que reaproximassem as ciências naturais e as ciências do espírito ou ciências humanas. Nessa sua tentativa, Goethe foi, sem exageros, a sua maior inspiração filosófica.

Apesar de não aceitar as críticas de Goethe à ótica newtoniana, foi com o uso da noção de ordenação da realidade que o físico alemão conseguiu encontrar um modo de dar razão ao autor de Fausto e ao filósofo natural inglês. A conceção de realidade 
do seu compatriota era mais complexa do que a do segundo. $\mathrm{Na}$ raiz da análise de Heisenberg, encontra-se a tese de que a física moderna poderia mostrar os limites da atividade de pesquisa sobre a natureza.

Uma última palavra. Analisada a partir dos nossos dias, não me parece muito difícil reconhecer que a atitude crítica de Goethe faz sentido. A sua motivação principal ao analisar criticamente a ótica de Newton ainda hoje é válida. Tentar justificar a separação, ou divisão, entre os diferentes domínios da atividade intelectual humana exige um preço excessivo, o qual poucos parecem dispostos a pagar, excetuando-se talvez aqueles que acreditam no atual sistema sócio-político, nomeadamente determinado por valores e objetivos economicistas e financeiros. A despeito de nossa incapacidade de encontrar soluções para alguns problemas decorrentes da presença efetiva dessa divisão, como, a título de exemplo, o excessivo e pernicioso especialismo, não creio que isso deva nos levar a desistir de refletir sobre as críticas que Goethe fez à ciência moderna. Não creio ser necessário aceitá-las na sua íntegra para que se possa buscar encontrar uma solução para os nossos dilemas. Mesmo que as nossas forças (materiais e espirituais) sejam menores do que gostaríamos que fossem, persistir é necessário, uma vez que estamos sempre envolvidos pela natureza; energias extras podem ser conseguidas caso seja mantida a crença na criatividade humana. 